\title{
On the oxygen reduction reaction in phosphoric acid electrolyte: evidence of significantly increased inhibition at steady state conditions
}

\author{
Yu-Jia Deng ${ }^{a}$, Gustav Karl Henrik Wiberga,b, Alessandro Zana ${ }^{a}$, Matthias Arenz ${ }^{\text {a,c* }}$ \\ ${ }^{a}$ Nano-Science Center, Department of Chemistry, University of Copenhagen, Universitetsparken 5, \\ DK-2100 Copenhagen $\emptyset$, Denmark \\ ${ }^{\mathrm{b}}$ Nordic Electrochemistry ApS \\ ${ }^{c}$ Department of Chemistry and Biochemistry, University of Bern, Freiestrasse 3, 3012 Bern, \\ Switzerland
}

Phone: +41-31 63153 84; Fax: +41316313994

* Corresponding Author: matthias.arenz@dcb.unibe.ch

Keywords: Anion Adsorption, Phosphoric acid electrolyte, HT-PEMFC, Oxygen reduction reaction, Pt, Viscoelectric Effect

\begin{abstract}
In the presented work, we investigate the oxygen reduction reaction (ORR) in half-cell measurements employing different electrolytes. The aim is to compare the ORR inhibition due to anion adsorption at transient as well as steady state conditions. It is found that the ORR inhibition at the platinum - phosphoric acid electrolyte interface is a relative slow, time dependent process. The major inhibition is not observed in transient polarization curves but only under steady state
\end{abstract}


conditions. This observation is in contrast to the typical ORR inhibition due to anion adsorption as observed for example in sulfuric acid electrolyte. In sulfuric acid the inhibition is fast and then stays more or less constant in time. As a consequence of our findings, common transient measurements of the ORR activity might not be sufficient to investigate suitable mitigation strategies for the ORR inhibition in phosphoric acid electrolyte. Such strategies need to take steady state conditions into account.

In order to explain the slow ORR inhibition in phosphoric acid electrolyte, two possible explanations are discussed. Either the adsorption of phosphate is a slow, complex process, where a fast adsorption step is followed by a consecutive filling of the surface, or a mass transfer barrier develops at the polarized phosphoric acid - electrode interface. The latter might be the viscoelectric effect that is known from colloidal science.

\section{Introduction}

The electrochemical interface and specific anion adsorption on metal surfaces are subject to numerous studies regarding their influence on electrocatalytic reactions, see for example refs. [1-14] for an overview. Most studies are related to surface science and therefore target the structure sensitivity of anion adsorption on well-defined single crystal surfaces. For the oxygen reduction reaction (ORR) on $\mathrm{Pt}$, it was for example shown that not only electronic and geometric properties determine the ORR activity $[15,16]$, but the structure sensitive anion adsorption leads to the blocking of reaction sites, therefore severely inhibiting the reaction for specific surface geometries [4-6, 17-20]. In other words, the structure sensitivity observed for the ORR, is not only due to a structure sensitive ORR process, but also due to structure sensitive anion adsorption. In this respect, the site blocking model gave a very elegant explanation for the different order in ORR activity when comparing low index Pt single crystal surfaces in sulfuric acid and perchloric acid electrolyte, respectively [1]. In addition it could explain the positive effect of adsorbed cyanide anions on the 
ORR activity in sulfuric and phosphoric acid electrolyte [21]. However, so far the experimental investigations have been performed under transient conditions, i.e. cycling the electrode potential. It is assumed that the adsorption process is fast and that therefore the anion coverage on the electrode always is in equilibrium [22]. To the best of our knowledge no previous investigations of the time dependence of these processes were performed that highlight the significant differences between the behavior of sulfuric and phosphoric acid. In contrast in general it is assumed that anion adsorption from phosphoric and sulfuric acid act similar, while perchloric acid exhibits only weak or no blocking [1, 2, 23-27].

Anion adsorption has also severe practical consequences in electrocatalysis, e.g. for phosphoric acid based fuel cells. Phosphoric acid fuel cells (PAFCs) were the first commercially successful fuel cells, but never entered the mass market due to their high costs. However, PAFCs gained renewed interest with the invention to embed the liquid acid electrolyte in a matrix of polybenzimidazole (PBI) [28]. This type of fuel cell is now typically referred to as high temperature proton exchange membrane fuel cell (HT-PEMFC) [29, 30]. The higher operating temperature of HT-PEMFCs as compared to low temperature (LT) PEMFCs has several advantages. For example it provides a higher $\mathrm{CO}$ tolerance and produces water vapor instead of liquid water as product. Yet the reaction rate of the ORR is significantly lower than expected from the high operation temperature. This inhibition of the ORR rate represents one of the major hurdles for the economic success of HTPEMFCs. Often it is associated with the same site blocking mechanism observed in electrochemical half-cells, where the phosphate anions completely block the active sites of Pt. Alternatively - or in addition - the low solubility of oxygen in concentrated phosphoric acid was highlighted to explain the poor performance [30-35].

Studies using in electrochemical half-cells to investigate possible mitigation strategies for the ORR inhibition in phosphoric acid are in general performed at transient conditions. In the presented work, 
we scrutinize the underlying phenomena of the poor performance of HT-PEMFCs by investigating the time dependent influence of different anions on the ORR. In contrast to previous measurements we concentrate on the steady state behavior in different acidic electrolytes. The main aim is to show that in contrast to previous assumptions there is a considerable difference between the site blocking in sulfuric acid electrolyte and the inhibition observed in phosphoric acid.

\section{Experimental}

All electrochemical measurements were conducted in an in house developed three-compartment electrochemical cell made out of Teflon [36, 37]. A saturated calomel electrode (SCE), separated from the working electrode compartment by a membrane, was used as the reference electrode [38]. However, all potentials in this study refer to that of the reversible hydrogen electrode (RHE), which was experimentally determined by measuring the hydrogen evolution (HER) and hydrogen oxidation reaction (HOR). All electrolyte solutions, i.e. $0.1 \mathrm{M} \mathrm{HClO}_{4}, 0.05 \mathrm{M} \mathrm{H}_{2} \mathrm{SO}_{4}$ and $0.75 \mathrm{M}$ $\mathrm{H}_{3} \mathrm{PO}_{4}$ were made with Suprapure grade chemicals and Millipore water (Resistivity $=18.2 \mathrm{M} \Omega \mathrm{cm}$, TOC $<5 \mathrm{ppb}$ ). For experiments in $0.1 \mathrm{M} \mathrm{HClO}_{4}$ with varying amounts of $\mathrm{H}_{3} \mathrm{PO}_{4}, 0.5 \mathrm{M} \mathrm{H}_{3} \mathrm{PO}_{4}$ was added to the $0.1 \mathrm{M} \mathrm{HClO}_{4}$ electrolyte until the desired concentration was reached. In all measurements the electrolyte was constantly purged by $\mathrm{Ar}, \mathrm{H}_{2}$, or $\mathrm{O}_{2}$.

The working electrode was a polycrystalline $(\mathrm{PC}) \mathrm{Pt} \operatorname{disk}\left(\varnothing=5 \mathrm{~mm}, \mathrm{~A}=0.196 \mathrm{~cm}^{2}\right)$ mounted into the tip of a rotating disk electrode (RDE; Radiometer Analytical). The counter electrode was a Pt mesh. As only trends are investigated, all currents in this study are given in terms of geometric current densities $\left(\mathrm{mA} \mathrm{cm} \mathrm{cm}^{-2}\right)$ and all experiments were performed at room temperature. The roughness factor (ratio between real and geometric surface area) of the Pt electrode is around 1.71.9. The solution resistance was online recorded with the potentiostat (ECi-200 Nordic Electrochemistry) by superimposing a $5 \mathrm{kHz}, 5 \mathrm{mV}$ AC signal and compensated for by an analogue positive feedback scheme [39]. The effective solution resistance was around $2 \Omega$. The stripping 
procedure we employed for some of the experiments is explained in detail in previous work [40]. In short, in the automated measurement sequence (Software from Nordic Electrochemistry) we applied a voltage profile consisting of holding the potential for $100 \mathrm{~s}$ at a certain start value followed by recording a single cyclic voltammogram with a sweep rate of $500 \mathrm{mVs}^{-1}$. After the sweep a potential hold at the next potential value was applied. The current density measured at each potential hold after $100 \mathrm{~s}$ applying a rotation rate of $1600 \mathrm{rpm}$ is referred to as the steady state current density.

\section{Results and discussion}

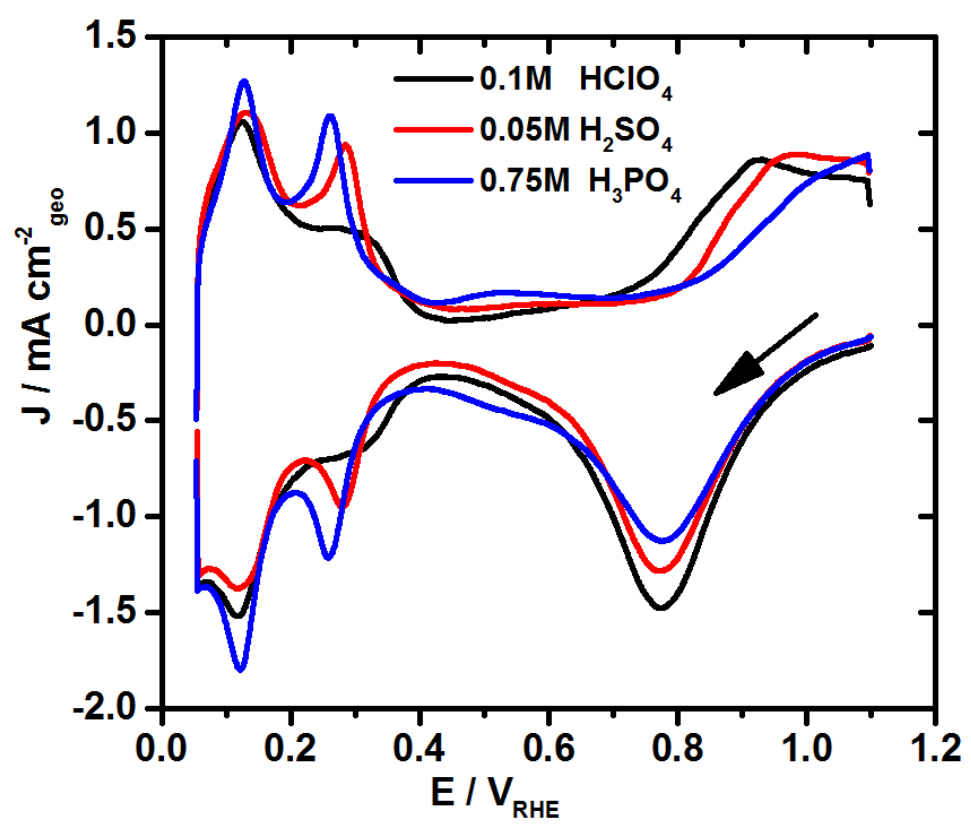

Figure 1. Polarization (stripping) curves recorded after potential hold for $100 \mathrm{~s}$ at $1.1 \mathrm{~V}_{\mathrm{RHE}}$ in $\mathrm{Ar}$ saturated $0.1 \mathrm{M} \mathrm{HClO}_{4}, 0.05 \mathrm{M} \mathrm{H}_{2} \mathrm{SO}_{4}$, and $0.75 \mathrm{M} \mathrm{H}_{3} \mathrm{PO}_{4}$ electrolyte respectively. All solutions have $\mathrm{pH} 1$. The scan rate was $0.5 \mathrm{~V} \mathrm{~s}^{-1}$.

As discussed in the introduction, the aim of this work was to study the time dependent influence of anion adsorption on the ORR at the Pt electrolyte interface with different electrolyte solutions. We 
start the discussion of our results with the basic electrochemical behavior of $\mathrm{Pt}$ in the three Ar saturated electrolytes $0.1 \mathrm{M} \mathrm{HClO}_{4}, 0.05 \mathrm{M} \mathrm{H}_{2} \mathrm{SO}_{4}$, and $0.75 \mathrm{M} \mathrm{H}_{3} \mathrm{PO}_{4}$ solution. We chose these concentrations in order to adjust all electrolytes to approximately $\mathrm{pH} 1 ; \mathrm{pH}$ values of $1.10\left(\mathrm{HClO}_{4}\right)$, $1.27\left(\mathrm{H}_{2} \mathrm{SO}_{4}\right)$, and $1.05\left(\mathrm{H}_{3} \mathrm{PO}_{4}\right)$ were determined by the measured potential of the reversible hydrogen reaction (HER/HOR) versus the SCE reference electrode.

In figure 1, polarization curves of $\mathrm{Pt}$ in contact with these electrolytes are shown. The start potential was held for $100 \mathrm{~s}$ at $1.1 \mathrm{~V}_{\mathrm{RHE}}$ and thereafter a single cyclic voltammogram was recorded - a procedure we previously dubbed as stripping procedure [40]. The obtained curves display the wellknown behavior of $\mathrm{Pt}$ in these electrolytes. Taking the polarization curve recorded in $0.1 \mathrm{M} \mathrm{HClO}_{4}$ as example, starting from $1.1 \mathrm{~V}_{\mathrm{RHE}}$ and scanning in negative direction, a peak at around $0.8 \mathrm{~V}_{\mathrm{RHE}}$ is seen, which usually is ascribed to the reduction of oxygenated species such as $\mathrm{Pt}-\mathrm{OH}_{\mathrm{ad}}$ and $\mathrm{Pt}-\mathrm{O}_{\mathrm{ad}}$ formed during the potential hold. In the adjacent potential region between 0.6 and $0.4 \mathrm{~V}_{\mathrm{RHE}}$ only capacitive currents from the double layer discharge are observed, while between 0.4 to $0.05 \mathrm{~V}_{\mathrm{RHE}}$ two peaks due to hydrogen underpotential deposition $\left(\mathrm{H}_{\mathrm{upd}}\right)$ arise. In the subsequent positive scan, the $\mathrm{H}_{\text {upd }}$ desorption and double layer charging processes give rise to anodic currents that are largely symmetrical to the respective cathodic process. By contrast, the formation of $\mathrm{Pt}-\mathrm{OH}_{\mathrm{ad}}$ and $\mathrm{Pt}-\mathrm{O}_{\mathrm{ad}}$ occurs at different potentials in the positive and negative going sweeps, and thus often is dubbed as irreversible.

Comparing the behavior of Pt in the three different acid electrolytes, the same peak positions for the reduction of oxygenated species are observed. Slight differences in the peak area indicate that a different amount of oxygenated species has been formed in each electrolyte. This is in line with the onset potential for the $\mathrm{Pt}-\mathrm{OH}_{\mathrm{ad}}$ formation found in the positive going scan. In perchloric acid electrolyte $\mathrm{Pt}-\mathrm{OH}_{\mathrm{ad}}$ formation starts at slightly lower potentials as compared to the other two electrolytes. The $\mathrm{H}_{\text {upd }}$ process displays an electrolyte dependent behavior as well. Unlike in $\mathrm{HClO}_{4}$ 
solution, the $\mathrm{H}_{\text {upd }}$ peak at around $0.3 \mathrm{~V}_{\mathrm{RHE}}$ gets more pronounced in $\mathrm{H}_{2} \mathrm{SO}_{4}$ and $\mathrm{H}_{3} \mathrm{PO}_{4}$ based electrolyte. It is shifted to more negative potentials, especially in the $\mathrm{H}_{3} \mathrm{PO}_{4}$ electrolyte solution [41, 42]. This observation demonstrates that the desorption/adsorption of strongly adsorbed anions influences the adsorption/desorption of hydrogen and shifts it to a lower potential [43]. As mentioned above, the onset potential for the formation of oxygenated species starts earlier (lower potential) in $\mathrm{HClO}_{4}$ than in the other two acids. As it is commonly accepted that adsorbed oxygenated species inhibit the ORR [44], from this behavior one could expect that the ORR is stronger inhibited in perchloric acid electrolyte as compared to sulfuric and phosphoric acid electrolyte; and not vice versa as in fact is observed (see below) [42]. This example shows that linking the observed activity to charges integrated in transient measurements can be misleading. Above, it was argued that anion adsorption starts concomitant to hydrogen desorption. One should keep in mind that cyclic voltammetry represents the behavior the majority of surface sites, which is not necessarily equal to the sites active for the ORR. Last but not least, cyclic voltammetry is a transient method and might not display the steady state properties. 


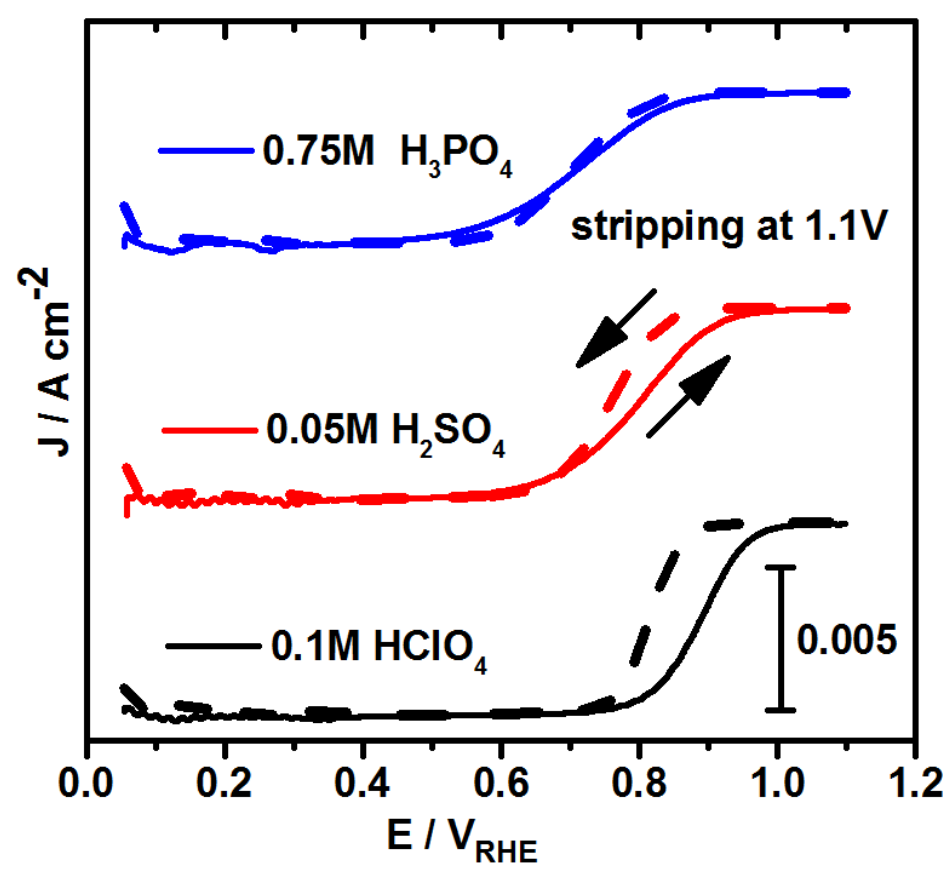

Figure 2. Polarization (stripping) curves recorded after potential hold for $100 \mathrm{~s}$ at $1.1 \mathrm{~V}_{\mathrm{RHE}}$ in $\mathrm{O}_{2}$ saturated $0.1 \mathrm{M} \mathrm{HClO}_{4}, 0.05 \mathrm{M} \mathrm{H}_{2} \mathrm{SO}_{4}$, and $0.75 \mathrm{M} \mathrm{H}_{3} \mathrm{PO}_{4}$ electrolyte, respectively. The scan rate was $0.5 \mathrm{~V} \mathrm{~s}^{-1}$, the rotation rate $1600 \mathrm{rpm}$. The polarization curves are background corrected, i.e., the respective CVs recorded in Ar saturated electrolyte are subtracted. The solid lines represent the positive going sweep, whereas the dashed lines represent the negative sweep.

We now compare the apparent ORR activities observed in the three electrolytes by repeating the same experimental protocol described above, but in oxygen saturated electrolyte. The polarization curves obtained after background correction are shown in Fig. 2. As background we used the equivalent polarization curves recorded in Ar saturated electrolyte and thus, separate the faradaic ORR current from the current contribution of other processes.

Beginning with the polarization curve recorded in $0.1 \mathrm{M} \mathrm{HClO}_{4}$, we see that when starting the stripping scan at $1.1 \mathrm{~V}_{\mathrm{RHE}}$ after a $100 \mathrm{~s}$ potential hold, at first no reduction currents are observed. The onset of the ORR current is around $0.9 \mathrm{~V}_{\mathrm{RHE}}$ and the kinetic limited current increases exponentially with decreasing the potential. Scanning further in negative direction the ORR current becomes mixed diffusion-kinetic limited and finally (below ca. $0.7 \mathrm{~V}_{\mathrm{RHE}}$ ) a pure diffusion limited 
reduction current of about $-6.6 \mathrm{~mA} \mathrm{~cm}^{-2}$ is reached. Between positive and negative going sweep a large hysteresis exists as seen by the difference in solid and dashed line. Comparing this behavior to the one observed in $0.05 \mathrm{M} \mathrm{H}_{2} \mathrm{SO}_{4}$, and $0.75 \mathrm{M} \mathrm{H}_{3} \mathrm{PO}_{4}$ electrolyte, several differences are apparent: i) The hysteresis of the polarization curves increases in the order of $\mathrm{H}_{3} \mathrm{PO}_{4}<\mathrm{H}_{2} \mathrm{SO}_{4}<\mathrm{HClO}_{4}$; in fact in $\mathrm{H}_{3} \mathrm{PO}_{4}$ almost no hysteresis is observed; ii) the diffusion limited current density in $0.75 \mathrm{M} \mathrm{H}_{3} \mathrm{PO}_{4}$ is lower than that in $0.05 \mathrm{M} \mathrm{H}_{2} \mathrm{SO}_{4}$ and $0.1 \mathrm{M} \mathrm{HClO}_{4}$. That is around $-5.2 \mathrm{~mA} \mathrm{~cm}^{-2}$ as compared to $6.6 \mathrm{~mA} \mathrm{~cm}{ }^{-2}$, a difference that can be ascribed to the reduced solubility and/or diffusion of $\mathrm{O}_{2}$ in $0.75 \mathrm{M} \mathrm{H}_{3} \mathrm{PO}_{4}$ due to high salt content $[45,46]$. As discussed in the introduction, the low oxygen solubility of phosphoric acid is known and regarded as one of the reasons for the low current densities observed in high-temperature PEMFCs [31, 47]. The difference in hysteresis between the polarization curves recorded in the different acids, however, is less known. It is very intriguing that in the mixed kinetic/diffusion controlled potential region of the ORR in $0.75 \mathrm{M} \mathrm{H}_{3} \mathrm{PO}_{4}$ almost no hysteresis is seen, as if the process is in steady state; a hysteresis indicates non-equilibrium conditions - mostly of the coverage with oxygenated species - during the potential scan $[39,44,48]$. 


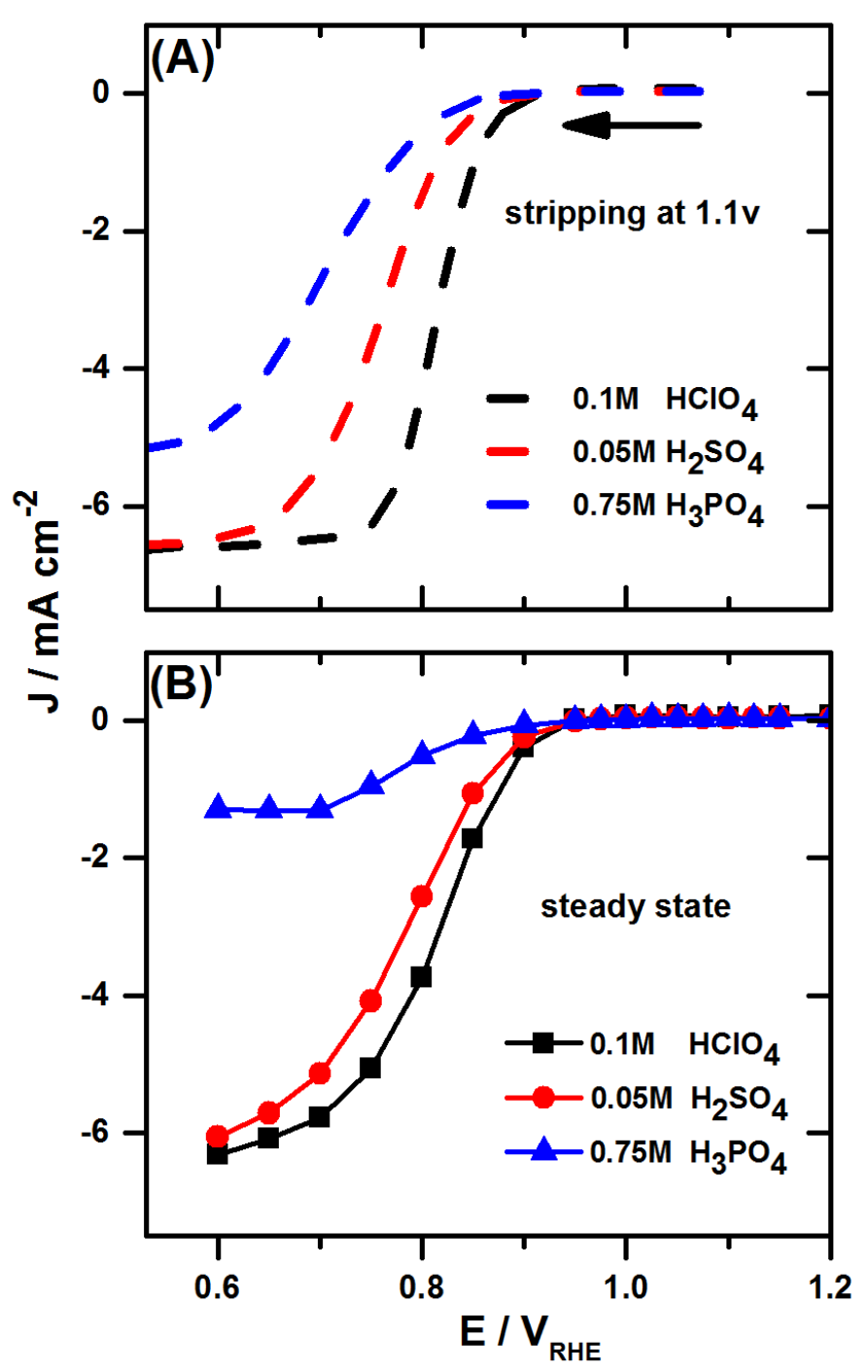

Figure 3. (A) Re-plot of the negative going stripping curves from Figure 2, i.e. the ORR current transients. (B) Corresponding steady state current densities. As steady state current densities we thereby define the ORR rate measured in $\mathrm{O}_{2}$ saturated $0.1 \mathrm{M} \mathrm{HClO}_{4}, 0.05 \mathrm{M} \mathrm{H}_{2} \mathrm{SO}_{4}$, and $0.75 \mathrm{M}$ $\mathrm{H}_{3} \mathrm{PO}_{4}$ electrolyte solutions after a potential hold of $100 \mathrm{~s}$. A constant rotation rate of $1600 \mathrm{rpm}$ was applied. For the measurement we started at a potential of $0.6 \mathrm{~V}$ RHE and increased the potential in steps as indicated. The lines between the points only serve as a guide for the eye.

Therefore we investigated in the next step the difference between the transient technique of recording polarization curves versus steady state conditions (potential hold for $100 \mathrm{~s}$ ) - a more fuel cell like condition [40]. In Figure 3 we compare the ORR current transients (Fig. 3A) with the steady state ORR currents (Fig. 3B). The stripping curves shown in Figure 3A are identical to those 
shown in Figure 2. The differences in apparent ORR activity of Pt in the three electrolytes $(0.1 \mathrm{M}$ $\mathrm{HClO}_{4}>0.05 \mathrm{M} \mathrm{H}_{2} \mathrm{SO}_{4}>0.75 \mathrm{M} \mathrm{H}_{3} \mathrm{PO}_{4}$.), but also the reduced oxygen solubility in phosphoric acid are easily recognizable. Despite these differences, it is also seen that when applying the stripping technique the onset of the ORR is relatively independent of the electrolyte, i.e. slightly above $0.9 \mathrm{~V}_{\text {RHE}}$. This is consistent to the behavior under steady state conditions, where ORR current is only observed at the electrode potential below $0.95 \mathrm{~V}_{\mathrm{RHE}}$. Also the trend in apparent ORR activity is the same as observed under transient conditions. However at lower potentials the apparent ORR activity in $0.75 \mathrm{M} \mathrm{H}_{3} \mathrm{PO}_{4}$ is extremely reduced under steady state conditions, whereas the ORR is much less affected in $0.05 \mathrm{M} \mathrm{H}_{2} \mathrm{SO}_{4}$ and $0.1 \mathrm{M} \mathrm{HClO}_{4}$. That is, the observed steady state ORR current density is reduced in these electrolytes (as compared to the transient curve), but only slightly. The trend is the same and diffusion limited currents are reached (it should be mentioned that when calculating the kinetic ORR current densities, these relatively small differences would still lead to considerable differences). This is not the case for $0.75 \mathrm{M} \mathrm{H}_{3} \mathrm{PO}_{4}$ electrolyte. Under steady state the ORR is extremely inhibited and even at high overpotentials the absolute value of the apparent "limiting current density" is lower than $2 \mathrm{~mA} \mathrm{~cm}^{-2}$. We can therefore state that the observed steady state behavior of phosphoric acid is considerably different than the one observed in sulfuric or perchloric acid, see also supporting information. There it is shown that in sulfuric acid a ten time increase in anion concentration only reduces the diffusion limited current by $\sim 15 \%$, which can be ascribed to reduced oxygen solubility and reduced bulk diffusion [46, 49]. Most importantly, the difference between transient and steady state exhibits only minor concentration dependency, which is in stark contrast to phosphoric acid electrolyte. To highlight this point in Figure 4, we compare the time dependent ORR rate at a fixed electrode potential of $0.6 \mathrm{~V}_{\mathrm{RHE}}$. In $0.75 \mathrm{M} \mathrm{H}_{3} \mathrm{PO}_{4}$ electrolyte, the ORR current drops significantly over a period of $100 \mathrm{~s}$ and even then not a real steady state activity is observed. By contrast in $0.5 \mathrm{M} \mathrm{H}_{2} \mathrm{SO}_{4}$ electrolyte the ORR current is almost constant in 
time and only a small, linear decrease with time is observed. These measurements demonstrate that there is an unambiguous difference between the ORR inhibition in the two electrolytes.

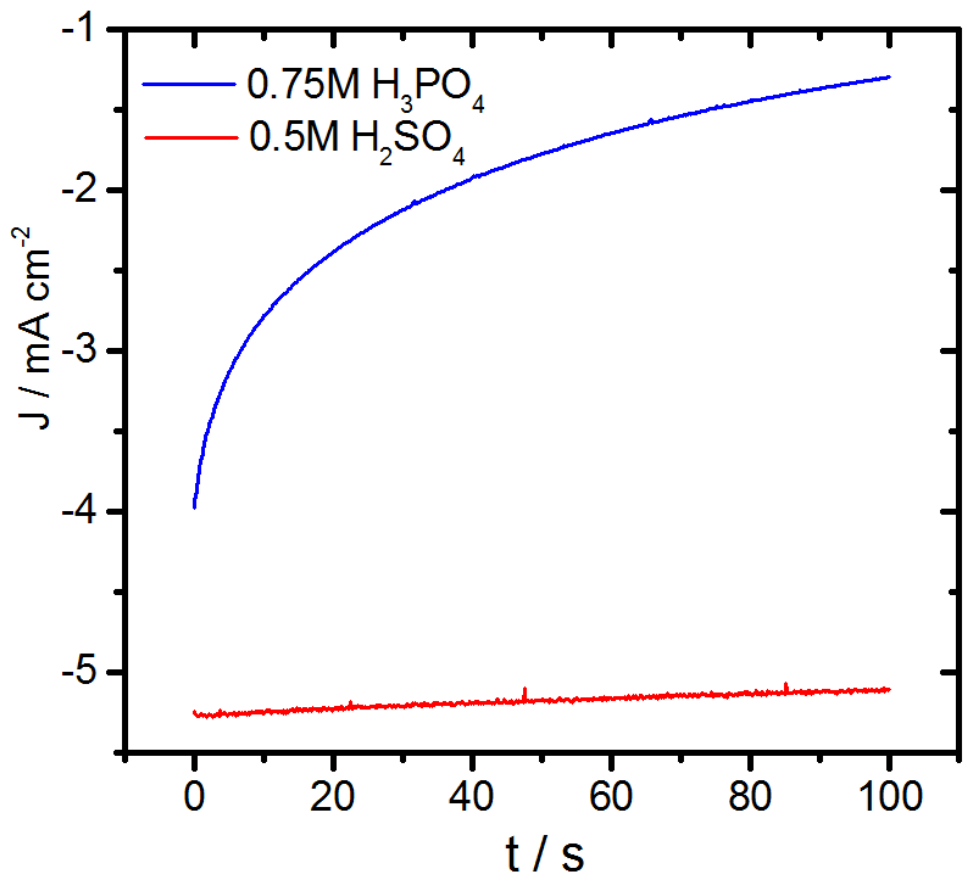

Figure 4. Time dependent $\mathrm{ORR}$ rate measured in $\mathrm{O}_{2}$ saturated $0.5 \mathrm{M} \mathrm{H}_{2} \mathrm{SO}_{4}$ (red line) and $0.75 \mathrm{M}$ $\mathrm{H}_{3} \mathrm{PO}_{4}$ (blue line) electrolyte solutions for a potential hold of $100 \mathrm{~s}$ at $0.6 \mathrm{~V}$ RHE. A constant rotation rate of $1600 \mathrm{rpm}$ was applied during the potential hold. 


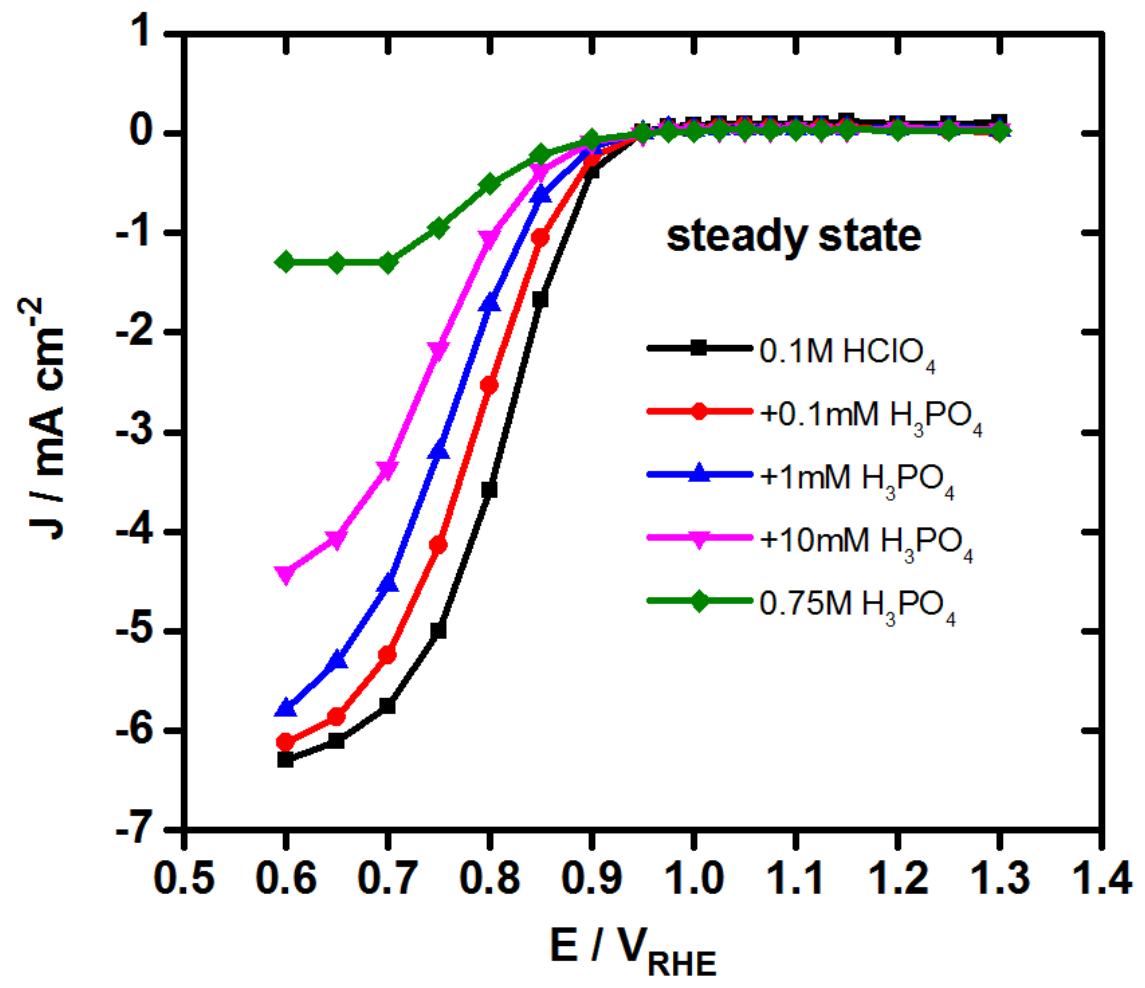

Figure 5. Steady state ORR current densities measured in $\mathrm{O}_{2}$ saturated $0.1 \mathrm{M} \mathrm{HClO}_{4}$ and $0.1 \mathrm{M}$ $\mathrm{HClO}_{4}$ with different amounts of $\mathrm{H}_{3} \mathrm{PO}_{4}$ added. We used that same measurement procedure as for the data shown in Figure 3. The lines between the points only serve as a guide for the eye.

To highlight that the observed extreme inhibition in $0.75 \mathrm{M} \mathrm{H}_{3} \mathrm{PO}_{4}$ electrolyte is not due to reduced oxygen solubility and bulk diffusion, we conducted the same steady state ORR experiments in different concentrations of phosphoric acid added to $0.1 \mathrm{M} \mathrm{HClO}_{4}$. The results are shown in Figure 5. It is seen that the addition of $10 \mathrm{mM} \mathrm{H}_{3} \mathrm{PO}_{4}$ to $0.1 \mathrm{M} \mathrm{HClO}_{4}$ leads to a distinctive reduction in the diffusion limited current. This concentration is sufficiently low to exclude a pronounced influence on the oxygen solubility or bulk diffusion properties, given that during potential sweep all mixtures exhibit almost the same diffusion limit (see supporting information).

The observed difference between the behavior in sulfuric and phosphoric acid electrolyte is intriguing both from applied and fundamental point of view. Considering the applied point of view, in recent years different factors have been proposed to be responsible for the reduced ORR activity 
in phosphoric acid, such as proton activity, double layer structure and site blocking by anion absorption $[50,51]$, the latter being the most popular concept. According to site blocking by anion absorption no fundamental difference between sulfuric and phosphoric acid would be expected. Anion adsorption is relative fast (as compared to the oxidation process) and accordingly a reduced hysteresis (as compared to perchloric acid) is found in the electrolytes where anion blocking takes place. As the adsorption process is considered fast, it is standard in the literature to analyze anion adsorption isotherms based on cyclic voltammetry performed at a scan rate of $50 \mathrm{mV} \mathrm{s}^{-1}$. As a consequence electrochemical half-cell investigations exploring mitigation strategies for the strong inhibiting effect of phosphoric acid use transient polarization curves in order to do so [21, 52]. Our results, however, show that the major inhibition takes place after several seconds (see figure 4), not in transient polarization curves. In addition HT-PEMFCs are not applied under highly dynamic conditions, such as automobile applications, but steady state. Thus mitigation strategies for the phosphoric acid inhibition should be tested under such conditions.

From an fundamental point of view, the observed activity inhibition in phosphoric acid is to some degree similar to the strong inhibiting effect of chloride contaminations [17, 53-55]. Thus one may consider contaminations being responsible for our observations. However, the effect of chloride contaminations is apparent (and is studied) under transient conditions. The inhibition effect is observed even in fast potential scans, whereas our results demonstrate that phosphoric acid inhibition is a relative slow process. Furthermore, all electrolytes were prepared from the highest available purity grade (surprapur). Based on inhibition due to contaminations, the inhibiting effect adding $10 \mathrm{mM} \mathrm{H}_{3} \mathrm{PO}_{4}$ (figure 5) should not be more significant than changing from 0.05 to $0.5 \mathrm{M}$ $\mathrm{H}_{2} \mathrm{SO}_{4}$ (figure $\mathrm{S} 1$ ).

We consider two possible mechanisms for the observed ORR inhibition: site blocking and the formation of a diffusion barrier. If the observed inhibition is entirely due to site blocking, the full 
extent of this process must be comparably slow - even though the site blocking is already apparent at fast scans as shown in the positive going curves of figure 2. A possible reason could be a fast adsorption process followed by a slow ordering of the anion adlayer, which slowly blocks remaining sites. In addition the different phosphate species could slowly change (transform) at the interface. According to our results (see figure 3B) between 0.6 and $0.7 \mathrm{~V}_{\mathrm{RHE}}$ the extent of blocking is constant and quite high. By contrast the determination of the anion coverage via charge integration would result in low coverage in this potential region, see CVs in figure 1.

Therefore, in addition to site blocking a diffusion barrier might slowly form at the interface. As mentioned above, low oxygen solubility is discussed as being responsible for the ORR inhibition in phosphoric acid [56]. Mitigating strategies try to enhance the local oxygen solubility at the electrode/electrolyte interface by introducing additives (such as ammonium trifluoromethanesulfonate) to the catalyst layer are reported [42, 57]. Based on the Levich equation [58], in standard RDE measurements the diffusion limited ORR current depends on the oxygen solubility in the electrolyte and the viscosity. Both are not distinguishable in RDE measurements, however, a local oxygen solubility should not be applicable in RDE measurements. By comparison an enhanced viscosity at the electrode-electrolyte interface would be possible. Such an effect is reported in colloid science where it is claimed that the viscosity of an electrolyte can increase due to a strong electric field $[59,60]$. The phenomenon is known as the viscoelectric effect (VEE) [61, 62]. Such a strong electric field exists at the electrode-electrolyte interface where the potential changes from the value of the electrode to that of the bulk electrolyte [63]. Recent studies using an atomic force microscope and molecular simulation claim an increase of viscosity up to a factor $10^{7}$ compared to bulk water at the $\sim 1 \mathrm{~nm}$ thick interface [64-66]. The Stokes-Einstein relation states that viscosity is inversely proportional to the diffusion coefficient, thus one would expect a significant reduction of the diffusion rate of reactants through such a viscous interface layer. 
Mass transport barriers at the polarized metal - electrolyte interface in phosphoric acid have not been - to the best of our knowledge - studied before. Experimentally they are difficult to prove and additional measurements will be necessary to pursue this idea. A diffusion barrier would, however, explain the positive effect of additives to the electrode layer on the ORR [42]. In RDE measurements the local oxygen concentration cannot be enhanced, however, the mass transport through the interface could be. Although any polarized interface should exhibit the VEE, a possible reason that the diffusion barrier in phosphoric acid electrolytes is much more pronounced than in the other electrolytes could be that the $\mathrm{pK}_{\mathrm{a}}$ values of perchloric and sulfuric acid (for the first deprotonation) are considerably lower than of phosphoric acid. At $\mathrm{pH}$ 1, phosphoric acid is only partially deprotonated and it is at equilibrium with pyrophosphoric acid and other polyphosphoric acids. Under the extreme conditions at a polarized interface, the equilibrium concentration of respective acid can be pushed towards the polyphosphoric acids, which are known to have a significant viscosity.

\section{Conclusion}

In recent years different factors have been proposed to be responsible for the reduced ORR activity in phosphoric acid. The most popular concept is based on a site blocking effect due to anion adsorption. This explains why in electrolytes such as sulfuric acid the ORR is much lower than in perchloric acid and in addition different structure sensitivities on Pt single crystals in the two electrolytes are observed [1]. In our work, we have shown that two supposedly strongly adsorbing electrolytes, sulfuric and phosphoric acid solutions, behave considerably different. The main inhibition of the ORR in phosphoric acid electrolyte becomes apparent only under steady state conditions. This is an important finding as strategies for mitigating the inhibition need to consider such conditions. A possible reason for the difference between sulfuric and phosphoric acid electrolyte could be that the $\mathrm{pK}_{\mathrm{a}}$ value of sulfuric acid is considerably lower than of phosphoric acid. 
At steady state conditions, the equilibrium concentration of phosphoric acid might slowly be pushed towards the polyphosphoric acids, thus forming either a denser adsorption layer or enhancing the viscosity at the interface. Additives to the electrode layer such as ammonium trifluoromethanesulfonate might positively influence the ORR by changing the dielectric constant of the interface [67].

\section{Acknowledgments}

Y-J.D. acknowledges funding from the China Scholarship Council (CSC). This work was supported by the Danish Council for Strategic Research (4M Centre).

\section{References}

[1] N.M. Markovic, P.N. Ross, Surface science studies of model fuel cell electrocatalysts, Surf Sci Rep, 45 (2002) 121-229.

[2] S. Ye, H. Kita, A. Aramata, Hydrogen and anion adsorption at platinum single crystal electrodes in phosphate solutions over a wide range of pH, Journal of Electroanalytical Chemistry, 333 (1992) 299-312. [3] R. Gisbert, G. García, M.T.M. Koper, Adsorption of phosphate species on poly-oriented Pt and Pt(1 111$)$ electrodes over a wide range of pH, Electrochimica Acta, 55 (2010) 7961-7968.

[4] A. Kuzume, E. Herrero, J.M. Feliu, Oxygen reduction on stepped platinum surfaces in acidic media, Journal of Electroanalytical Chemistry, 599 (2007) 333-343.

[5] N.M. Markovic, H.A. Gasteiger, B.N. Grgur, P.N. Ross, Oxygen reduction reaction on Pt(111): effects of bromide, Journal of Electroanalytical Chemistry, 467 (1999) 157-163.

[6] N.M. Markovic, H.A. Gasteiger, P.N. Ross, Oxygen Reduction on Platinum Low-Index Single-Crystal Surfaces in Sulfuric-Acid-Solution - Rotating Ring-Pt(Hkl) Disk Studies, J Phys Chem-Us, 99 (1995) 3411-3415. [7] Q. He, X. Yang, W. Chen, S. Mukerjee, B. Koel, S. Chen, Influence of phosphate anion adsorption on the kinetics of oxygen electroreduction on low index Pt(hkl) single crystals, Physical Chemistry Chemical Physics, 12 (2010) 12544-12555.

[8] T. Heaton, C. Friesen, Pt $\{111\}$ and Au\{111\} Electrocapillarity: Interphase Structure, the pzc, and Oxygen Reduction, The Journal of Physical Chemistry C, 111 (2007) 14433-14439.

[9] K.-Y. Yeh, S.A. Wasileski, M.J. Janik, Electronic structure models of oxygen adsorption at the solvated, electrified Pt(111) interface, Physical Chemistry Chemical Physics, 11 (2009) 10108-10117.

[10] A.P. Sandoval-Rojas, A.M. Gómez-Marín, M.F. Suárez-Herrera, V. Climent, J.M. Feliu, Role of the interfacial water structure on electrocatalysis: Oxygen reduction on $\operatorname{Pt}\left(\begin{array}{lll}1 & 1 & 1\end{array}\right)$ in methanesulfonic acid, Catal Today, 262 (2016) 95-99.

[11] J. Speder, A. Zana, M. Arenz, The colloidal tool-box approach for fuel cell catalysts: Systematic study of perfluorosulfonate-ionomer impregnation and Pt loading, Catal Today, 262 (2016) 82-89.

[12] S. Ye, H. Kita, A. Aramata, Hydrogen and Anion Adsorption at Platinum Single-Crystal Electrodes in Phosphate Solutions over a Wide-Range of Ph, Journal of Electroanalytical Chemistry, 333 (1992) 299-312. 
[13] M. Weber, F.C. Nart, I.R. deMoraes, T. Iwasita, Adsorption of phospbate species on Pt(111) and Pt(100) as studied by in situ FTIR spectroscopy, J Phys Chem-Us, 100 (1996) 19933-19938.

[14] A. Tanaka, R. Adzic, B. Nikolic, Oxygen reduction on single crystal platinum electrodes in phosphoric acid solutions, J Serb Chem Soc, 64 (1999) 695-705.

[15] Y.J. Deng, V. Tripkovic, J. Rossmeisl, M. Arenz, Oxygen Reduction Reaction on Pt Overlayers Deposited onto a Gold Film: Ligand, Strain, and Ensemble Effect, Acs Catal, 6 (2016) 671-676.

[16] J.K. Norskov, J. Rossmeisl, A. Logadottir, L. Lindqvist, J.R. Kitchin, T. Bligaard, H. Jonsson, Origin of the overpotential for oxygen reduction at a fuel-cell cathode, J. Phys. Chem. B, 108 (2004) 17886-17892.

[17] V. Stamenkovic, N.M. Markovic, P.N. Ross, Structure-relationships in electrocatalysis: oxygen reduction and hydrogen oxidation reactions on $\mathrm{Pt}(111)$ and $\mathrm{Pt}(100)$ in solutions containing chloride ions, Journal of Electroanalytical Chemistry, 500 (2001) 44-51.

[18] B.N. Grgur, N.M. Markovic, P.N. Ross, Temperature dependent oxygen electrochemistry on platinum low index single crystal surfaces in acid solutions, Can J Chem, 75 (1997) 1465-1471.

[19] A.M. Gomez-Marin, J.M. Feliu, New Insights into the Oxygen Reduction Reaction Mechanism on Pt(111): A Detailed Electrochemical Study, Chemsuschem, 6 (2013) 1091-1100.

[20] M.D. Macia, J.M. Campina, E. Herrero, J.M. Feliu, On the kinetics of oxygen reduction on platinum stepped surfaces in acidic media, Journal of Electroanalytical Chemistry, 564 (2004) 141-150.

[21] D. Strmcnik, M. Escudero-Escribano, K. Kodama, V.R. Stamenkovic, A. Cuesta, N.M. Markovic, Enhanced electrocatalysis of the oxygen reduction reaction based on patterning of platinum surfaces with cyanide, Nat Chem, 2 (2010) 880-885.

[22] J. Mostany, P. Martínez, V. Climent, E. Herrero, J.M. Feliu, Thermodynamic studies of phosphate adsorption on Pt(1 11 1) electrode surfaces in perchloric acid solutions, Electrochimica Acta, 54 (2009) 58365843.

[23] T.H.M. Housmans, M.T.M. Koper, CO oxidation on stepped $\mathrm{Rh}[\mathrm{n}(111) \times(111)]$ single crystal electrodes: Anion effects on CO surface mobility, Electrochem Commun, 7 (2005) 581-588.

[24] M. Ahmed, G.A. Attard, E. Wright, J. Sharman, Methanol and formic acid electrooxidation on nafion modified Pd/Pt $\{111\}$ : The role of anion specific adsorption in electrocatalytic activity, Catal Today, 202 (2013) 128-134.

[25] M. Osawa, M. Tsushima, H. Mogami, G. Samjeske, A. Yamakata, Structure of water at the electrified platinum-water interface: A study by surface-enhanced infrared absorption spectroscopy, J Phys Chem C, 112 (2008) 4248-4256.

[26] M. Nesselberger, M. Arenz, In Situ FTIR Spectroscopy: Probing the Electrochemical Interface during the Oxygen Reduction Reaction on a Commercial Platinum High-Surface-Area Catalyst, ChemCatChem, 8 (2016) 1-8.

[27] F.C. Nart, T. Iwasita, On the Adsorption of H2po4- and H3po4 on Platinum - an Insitu Ft-Ir Study, Electrochimica Acta, 37 (1992) 385-391.

[28] J.S. Wainright, J.T. Wang, D. Weng, R.F. Savinell, M. Litt, Acid-Doped Polybenzimidazoles - a New Polymer Electrolyte, J Electrochem Soc, 142 (1995) L121-L123.

[29] Q.F. Li, R.H. He, J.O. Jensen, N.J. Bjerrum, Approaches and recent development of polymer electrolyte membranes for fuel cells operating above 100 degrees C, Chemistry of Materials, 15 (2003) 4896-4915. [30] Q.F. Li, J.O. Jensen, R.F. Savinell, N.J. Bjerrum, High temperature proton exchange membranes based on polybenzimidazoles for fuel cells, Prog Polym Sci, 34 (2009) 449-477.

[31] Z.Y. Liu, J.S. Wainright, M.H. Litt, R.F. Savinell, Study of the oxygen reduction reaction (ORR) at Pt interfaced with phosphoric acid doped polybenzimidazole at elevated temperature and low relative humidity, Electrochimica Acta, 51 (2006) 3914-3923.

[32] S. Kaserer, K.M. Caldwell, D.E. Ramaker, C. Roth, Analyzing the Influence of H3PO4 as Catalyst Poison in High Temperature PEM Fuel Cells Using in-operando X-ray Absorption Spectroscopy, The Journal of Physical Chemistry C, 117 (2013) 6210-6217. 
[33] Q. He, B. Shyam, M. Nishijima, D. Ramaker, S. Mukerjee, Mitigating Phosphate Anion Poisoning of Cathodic Pt/C Catalysts in Phosphoric Acid Fuel Cells, The Journal of Physical Chemistry C, 117 (2013) 48774887.

[34] D.R. Desena, E.R. Gonzalez, E.A. Ticianelli, Effect of Phosphoric-Acid Concentration on the Oxygen Reduction and Hydrogen Oxidation Reactions at a Gas-Diffusion Electrode, Electrochimica Acta, 37 (1992) 1855-1858.

[35] S.J. Clouser, J.C. Huang, E. Yeager, Temperature-Dependence of the Tafel Slope for Oxygen Reduction on Platinum in Concentrated Phosphoric-Acid, J Appl Electrochem, 23 (1993) 597-605.

[36] K.J.J. Mayrhofer, A.S. Crampton, G.K.H. Wiberg, M. Arenz, Analysis of the impact of individual glass constituents on electrocatalysis on pt electrodes in alkaline solution, J Electrochem Soc, 155 (2008) P78-P81. [37] K.J.J. Mayrhofer, G.K.H. Wiberg, M. Arenz, Impact of glass corrosion on the electrocatalysis on Pt electrodes in alkaline electrolyte, J Electrochem Soc, 155 (2008) P1-P5.

[38] K.J.J. Mayrhofer, S.J. Ashton, J. Kreuzer, M. Arenz, An Electrochemical Cell Configuration Incorporating an Ion Conducting Membrane Separator between Reference and Working Electrode, Int J Electrochem Sc, 4 (2009) 1-8.

[39] G.K.H. Wiberg, The development of a state-of-the-art experimental setup demonstrated by the investigation of fuel cell reactions in alkaline electrolyte., http://mediatum.ub.tum.de?id=993285, 2010; http://mediatum.ub.tum.de?id=993285.

[40] G.K.H. Wiberg, M. Arenz, Establishing the potential dependent equilibrium oxide coverage on platinum in alkaline solution and its influence on the oxygen reduction, J Power Sources, 217 (2012) 262-267.

[41] P.N. Ross, P.C. Andricacos, The Effect of H2po4-Anion on the Kinetics of Oxygen Reduction on Pt, Journal of Electroanalytical Chemistry, 154 (1983) 205-215.

[42] K. Hoist-Olesen, M. Nesselberger, M. Perchthaler, V. Hacker, M. Arenz, Activity inhibition and its mitigation in high temperature proton exchange membrane fuel cells: The role of phosphoric acid, ammonium trifluoromethanesulfonate, and polyvinylidene difluoride, J Power Sources, 272 (2014) 10721077.

[43] Q.G. He, X.F. Yang, W. Chen, S. Mukerjee, B. Koel, S.W. Chen, Influence of phosphate anion adsorption on the kinetics of oxygen electroreduction on low index Pt(hkl) single crystals, Physical Chemistry Chemical Physics, 12 (2010) 12544-12555.

[44] H.A. Gasteiger, S.S. Kocha, B. Sompalli, F.T. Wagner, Activity benchmarks and requirements for Pt, Ptalloy, and non-Pt oxygen reduction catalysts for PEMFCs, Appl Catal B-Environ, 56 (2005) 9-35.

[45] F. Gan, D.T. Chin, Determination of Diffusivity and Solubility of Oxygen in Phosphoric-Acid Using a Transit-Time on a Rotating Ring-Disc Electrode, J Appl Electrochem, 23 (1993) 452-455.

[46] K.E. Gubbins, R.D. Walker, Solubility and Diffusivity of Oxygen in Electrolytic Solutions, J Electrochem Soc, 112 (1965) 469-471.

[47] Q.F. Li, H.A. Hjuler, N.J. Bjerrum, Oxygen reduction on carbon supported platinum catalysts in high temperature polymer electrolytes, Electrochimica Acta, 45 (2000) 4219-4226.

[48] Y.-J. Deng, M. Arenz, G.K.H. Wiberg, Equilibrium coverage of OHad in correlation with platinum catalyzed fuel cell reactions in $\mathrm{HClO} 4$, Electrochem. commun., 53 (2015) 41-44.

[49] R.N. Itoe, G.D. Wesson, E.E. Kalu, Evaluation of oxygen transport parameters in $\mathrm{H} 2 \mathrm{SO} 4-\mathrm{CH} 3 \mathrm{OH}$ mixtures using electrochemical methods, J Electrochem Soc, 147 (2000) 2445-2450.

[50] E.R. Gonzalez, K.L. Hsueh, S. Srinivasan, The Structure of the Double-Layer at the Mercury PhosphoricAcid Interface from Studies of Adsorption of Thiourea and Its Implications on Oxygen Reduction Kinetics, J Electrochem Soc, 130 (1983) 1-5.

[51] S.L. Chen, A. Kucernak, Electrocatalysis under conditions of high mass transport rate: Oxygen reduction on single submicrometer-sized Pt particles supported on carbon, J. Phys. Chem. B, 108 (2004) 3262-3276.

[52] J.E. Lim, U.J. Lee, S.H. Ahn, E. Cho, H.J. Kim, J.H. Jang, H. Son, S.K. Kim, Oxygen reduction reaction on electrodeposited PtAu alloy catalysts in the presence of phosphoric acid, Appl Catal B-Environ, 165 (2015) 495-502. 
[53] M. Arenz, V. Stamenkovic, T.J. Schmidt, K. Wandelt, P.N. Ross, N.M. Markovic, The effect of specific chloride adsorption on the electrochemical behavior of ultrathin Pd films deposited on $\mathrm{Pt}(111)$ in acid solution, Surf Sci, 523 (2003) 199-209.

[54] I. Katsounaros, J.C. Meier, K.J.J. Mayrhofer, The impact of chloride ions and the catalyst loading on the reduction of $\mathrm{H} 2 \mathrm{O} 2$ on high-surface-area platinum catalysts, Electrochimica Acta, 110 (2013) 790-795.

[55] N. Job, M. Chatenet, S. Berthon-Fabry, S. Hermans, F. Maillard, Efficient Pt/carbon electrocatalysts for proton exchange membrane fuel cells: Avoid chloride-based Pt salts!, J Power Sources, 240 (2013) 294-305. [56] X.A. Gang, H.A. Hjuler, C. Olsen, R.W. Berg, N.J. Bjerrum, Electrolyte Additives for Phosphoric-Acid FuelCells, J Electrochem Soc, 140 (1993) 896-902.

[57] S.G. Hong, K. Kwon, M.J. Lee, D.Y. Yoo, Performance enhancement of phosphoric acid-based proton exchange membrane fuel cells by using ammonium trifluoromethanesulfonate, Electrochem Commun, 11 (2009) 1124-1126.

[58] A.J. Bard, L.R. Faulkner, Electrochemical methods : fundamentals and applications, 2nd ed., Wiley, New York, 2001.

[59] E.N.D. Andrade, J. Hart, The Effect of an Electric Field on the Viscosity of Liquids .3., Proc R Soc Lon SerA, 225 (1954) 463-472.

[60] D. Stigter, On Viscoelectric Effect in Colloidal Solutions, J Phys Chem-Us, 68 (1964) 3600-\&.

[61] R.J. Hunter, Chapter 5 - Electroviscous and Viscoelectric Effects, in: R.J. Hunter (Ed.) Zeta Potential in Colloid Science, Academic Press1981, pp. 179-218.

[62] A.V. Delgado, F. Gonzalez-Caballero, R.J. Hunter, L.K. Koopal, J. Lyklema, Measurement and interpretation of electrokinetic phenomena, J Colloid Interf Sci, 309 (2007) 194-224.

[63] M.Z. Bazant, M.S. Kilic, B.D. Storey, A. Ajdari, Towards an understanding of induced-charge electrokinetics at large applied voltages in concentrated solutions, Adv Colloid Interfac, 152 (2009) 48-88.

[64] T.D. Li, J.P. Gao, R. Szoszkiewicz, U. Landman, E. Riedo, Structured and viscous water in subnanometer gaps, Phys Rev B, 75 (2007) 115415.

[65] J. Lyklema, S. Rovillard, J. De Coninck, Electrokinetics: The properties of the stagnant layer unraveled, Langmuir, 14 (1998) 5659-5663.

[66] S. Guriyanova, V.G. Mairanovsky, E. Bonaccurso, Superviscosity and electroviscous effects at an electrode/aqueous electrolyte interface: An atomic force microscope study, J Colloid Interf Sci, 360 (2011) 800-804.

[67] A. Fortunelli, W.A. Goddard, Y. Sha, T.H. Yu, L. Sementa, G. Barcaro, O. Andreussi, Dramatic Increase in the Oxygen Reduction Reaction for Platinum Cathodes from Tuning the Solvent Dielectric Constant, Angewandte Chemie International Edition, 53 (2014) 6669-6672. 


\section{Supporting information}

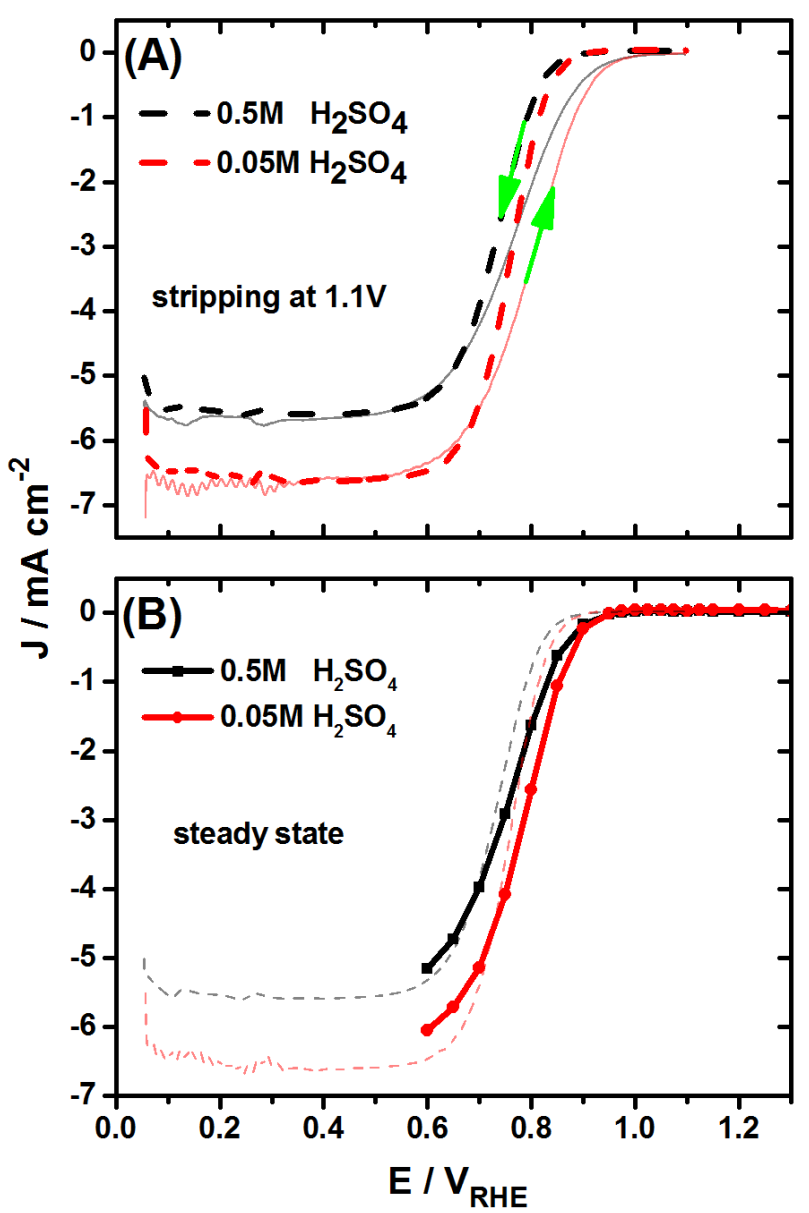

Figure S1. (A) Polarization (stripping) curves recorded after potential hold for $100 \mathrm{~s}$ at $1.1 \mathrm{~V}_{\mathrm{RHE}}$ in $\mathrm{O}_{2}$ saturated $0.05 \mathrm{M} \mathrm{H}_{2} \mathrm{SO}_{4}$, and $0.5 \mathrm{M} \mathrm{H}_{2} \mathrm{SO}_{4}$, respectively. The dashed curves indicate the (first) negative going sweep, the light solid line the concomitant positive going sweep. The scan rate was $0.5 \mathrm{Vs}^{-1}$, the rotation rate $1600 \mathrm{rpm}$. (B) Respective ORR currents at quasi steady state conditions, i.e. after a potential hold of 100s. The dashed lines indicate the stripping curves from Figure S1 (A). 


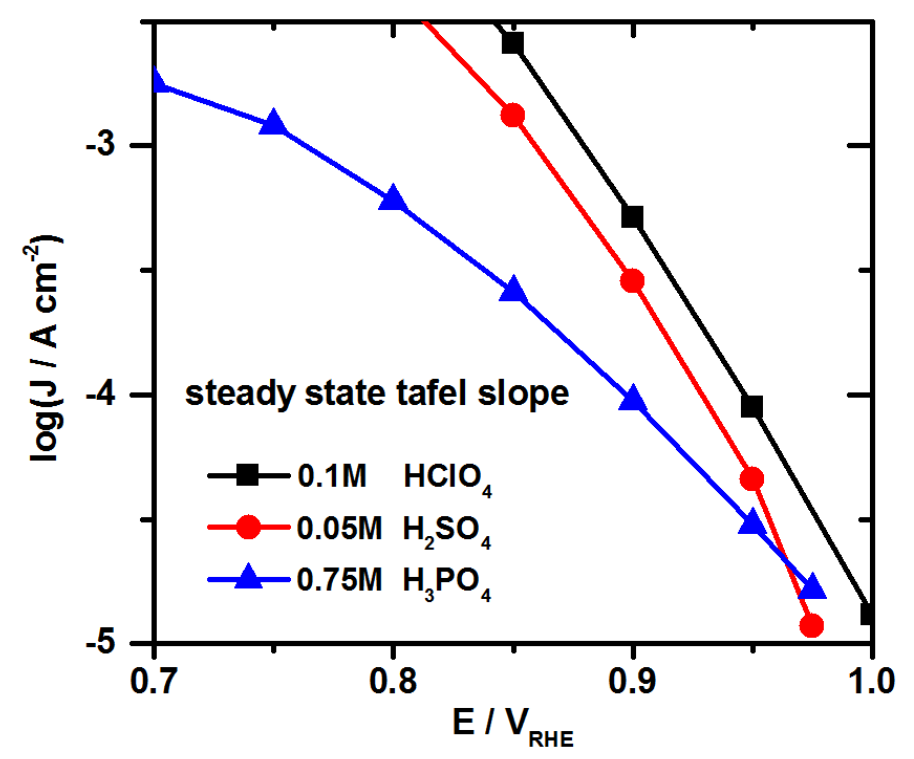

Figure S2. Tafel plots for the steady state ORR currents recorded in $\mathrm{O}_{2}$ saturated $0.1 \mathrm{M} \mathrm{HClO} 4$, $0.05 \mathrm{M} \mathrm{H}_{2} \mathrm{SO}_{4}$ and $0.75 \mathrm{M} \mathrm{H}_{3} \mathrm{PO}_{4}$, which are shown in Figure 3(B).

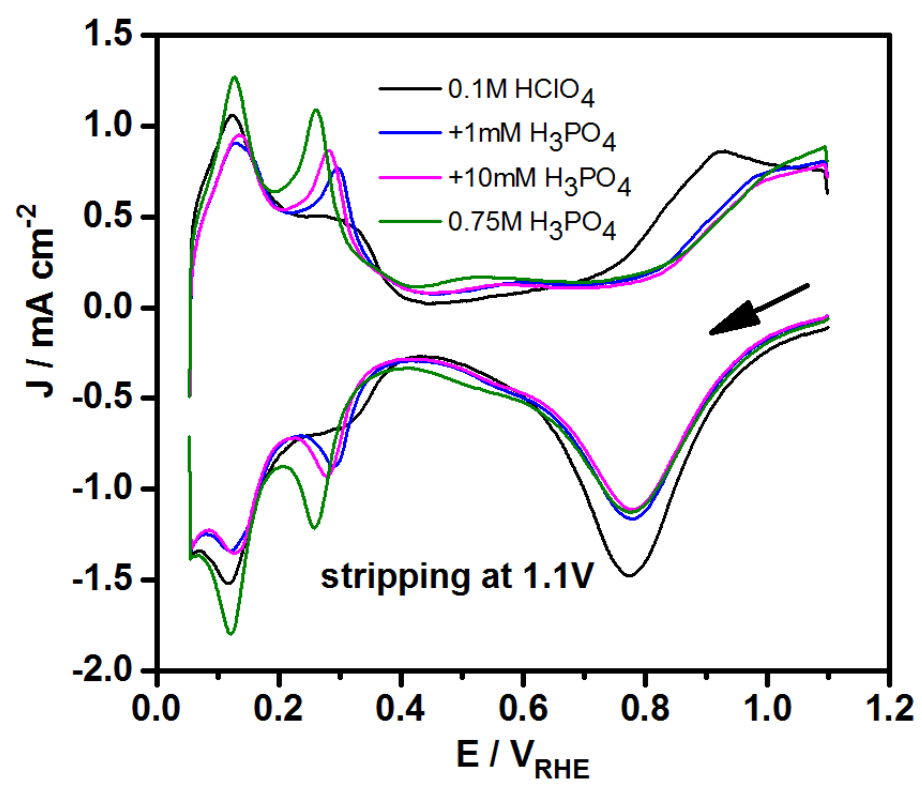

Figure S3. Polarization (stripping) curves recorded after potential hold for $100 \mathrm{~s}$ at $1.1 \mathrm{~V}_{\mathrm{RHE}}$ and the following positive scan curves recorded in $\mathrm{Ar}$ saturated $0.1 \mathrm{M} \mathrm{HClO}_{4}$ and $0.1 \mathrm{M} \mathrm{HClO}_{4}$ with different amounts of $\mathrm{H}_{3} \mathrm{PO}_{4}$ added solutions. The scan rate was $0.5 \mathrm{Vs}^{-1}$. 


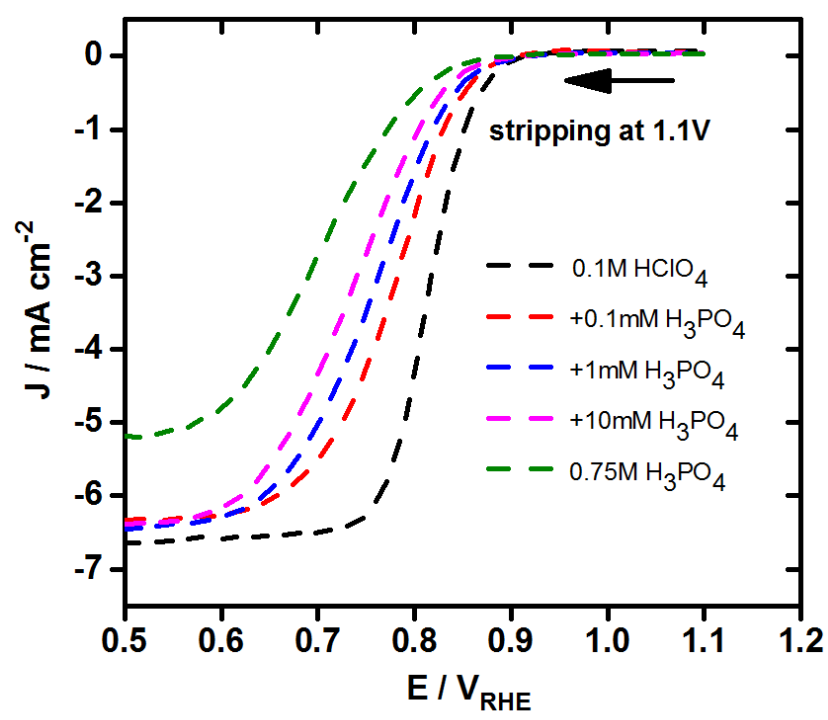

Figure S4. Polarization (stripping) curves recorded after potential hold for $100 \mathrm{~s}$ at $1.1 \mathrm{~V}_{\mathrm{RHE}}$ and the following positive scan curves recorded in $\mathrm{O}_{2}$ saturated $0.1 \mathrm{M} \mathrm{HClO}_{4}$ and $0.1 \mathrm{M} \mathrm{HClO}_{4}$ with different amounts of $\mathrm{H}_{3} \mathrm{PO}_{4}$ added solutions. The scan rate was $0.5 \mathrm{Vs}^{-1}$, the rotation rate $1600 \mathrm{rpm}$. 